\title{
We Still Don't Know How to Taper Glucocorticoids in Rheumatoid Arthritis, and We Can Do Better
}

Rheumatologists, internists, residents, and fellows frequently ask, "How do you taper glucocorticoids in rheumatoid arthritis?" Despite controlling symptoms of rheumatoid arthritis (RA) ${ }^{1}$ and slowing progression of radiological joint damage in early $\mathrm{RA}^{2}$, low-dose glucocorticoids (GC) are associated with a plethora of chronic adverse effects, including diabetes mellitus, hypertension, atherosclerosis, weight gain, osteoporosis, skin fragility, Cushingoid appearance, and myopathy, and are also associated with increased risk of infection, cardiovascular events, depression, cataracts, and skin atrophy ${ }^{3,4}$. To prevent or minimize these effects, GC tapering to the lowest dose necessary to maintain control of disease activity is recommended 5 .

However, strategies to taper GC vary, and are mostly described based on expert opinion. No clinical trials have directly examined, much less compared, different GC tapering regimens in $\mathrm{RA}^{5}$. Withdrawal of GC may also precipitate adverse events, including flare, adrenal insufficiency, and GC withdrawal syndrome ${ }^{6}$. To attempt to answer this frequent question, we performed a systematic literature review to assess the influence of tapering regimens on successful GC withdrawal, as well as clinical outcomes. We searched PubMed and Cochrane Central to identify publications from January 1972 to February 2011 (detailed search strategy available on request). Search terms comprised 4 blocks that were combined with Cochrane hedge, "methodological filter for clinical trials." The first block addressed disease (RA in adults); the second and third, intervention (GC/related terms AND tapering); and the fourth, outcome (withdrawal/dose reduction, effect on disease activity). We double-extracted all titles and abstracts according to the following: inclusion criteria: (a) adult patients with RA; (b) studies in which GC and related terms (e.g., corticosteroids, prednisone, prednisolone, etc.) were used; and exclusion criteria: (a) case report or case series with $<20$ patients; (b) editorials, review articles, letters, opinions, etc.

Two of our 4 reviewers (ERV, SR, DEF, TGW) independently reviewed and extracted data from the remaining articles and excluded an article if: (1) it did not include an oral GC; (2) it did not include and describe the GC tapering method; and/or (3) it was an extension of a study in which $\mathrm{GC}$ were not tapered during the extension period. Because we were interested only in studies that described a GC tapering method, we did not include studies in which GC were stopped abruptly without any dose reduction strategy.
We extracted data regarding patient characteristics, study design, interventions, and GC tapering, together with data for the influence of tapering in terms of continued disease control and any changes in adverse effects. Discordant assessments between 2 reviewers were resolved by discussion to achieve consensus.

Quality assessment was performed using the risk of bias tool from the Cochrane Collaboration ${ }^{7}$. We also examined heterogeneity in terms of study design and patient characteristics, as well as availability of data on adverse events and disease control during and after tapering, to determine whether a metaanalysis could be performed.

Of the initial 1265 articles (1091 identified in PubMed, 174 in Cochrane Central), 76 met criteria for detailed review, and after reading each article in depth, only 6 randomized controlled trials (RCT) met our selection criteria $8,9,10,11,12,13$. Four longterm extension (LTE) trials also provided data on tapering and withdrawal of GC as a secondary efficacy endpoint ${ }^{14,15,16,17}$.

Based on whether a study design included a specific tapering regimen, and whether efficacy and safety of GC were examined systematically during and after tapering, the quality of the RCT reports was limited for the objectives of our systematic literature review. In addition, while all the RCT reported sequence generation and allocation concealment, none randomized patients to different GC tapering regimens, and only 3 fully reported the outcomes (defined as description of effect on efficacy and at least 1 adverse event $)^{8,10,12}$. Given the variability in tapering regimens and the inconsistency in reporting outcomes, a metaanalysis could not be performed.

Baseline demographic and disease activity characteristics of the patients with RA in each RCT were similar (Table 1). However, disease duration varied, because some studies included only patients with early RA (mean $\leq 2$ years from the time of diagnosis) $)^{8,10,11,13}$, while other studies included patients who had established $\mathrm{RA}^{9,12}$.

Each RCT described a different tapering approach (Table 2). The majority of studies tapered the GC to $0 \mathrm{mg}$ daily $8,9,12,13$, while 2 studies tapered the GC to $7.5 \mathrm{mg}$ daily ${ }^{10,11}$. Only 1 study ${ }^{10}$ used a quantitative disease activity measure to stop the GC taper (Disease Activity Score-44 > 2.4). In an era when treatment targets have been defined to improve outcomes in patients with RA ${ }^{18}$, failure to use existing validated measures to guide $\mathrm{GC}$ tapering in $\mathrm{RCT}$ is disconcerting. Personal non-commercial use only. The Journal of Rheumatology Copyright @ ${ }^{2013}$. All rights reserved. 
Table 1. Description of randomized trials tapering glucocorticoids (GC) and baseline characteristics of all study participants. All values are n (\%), except where otherwise stated.

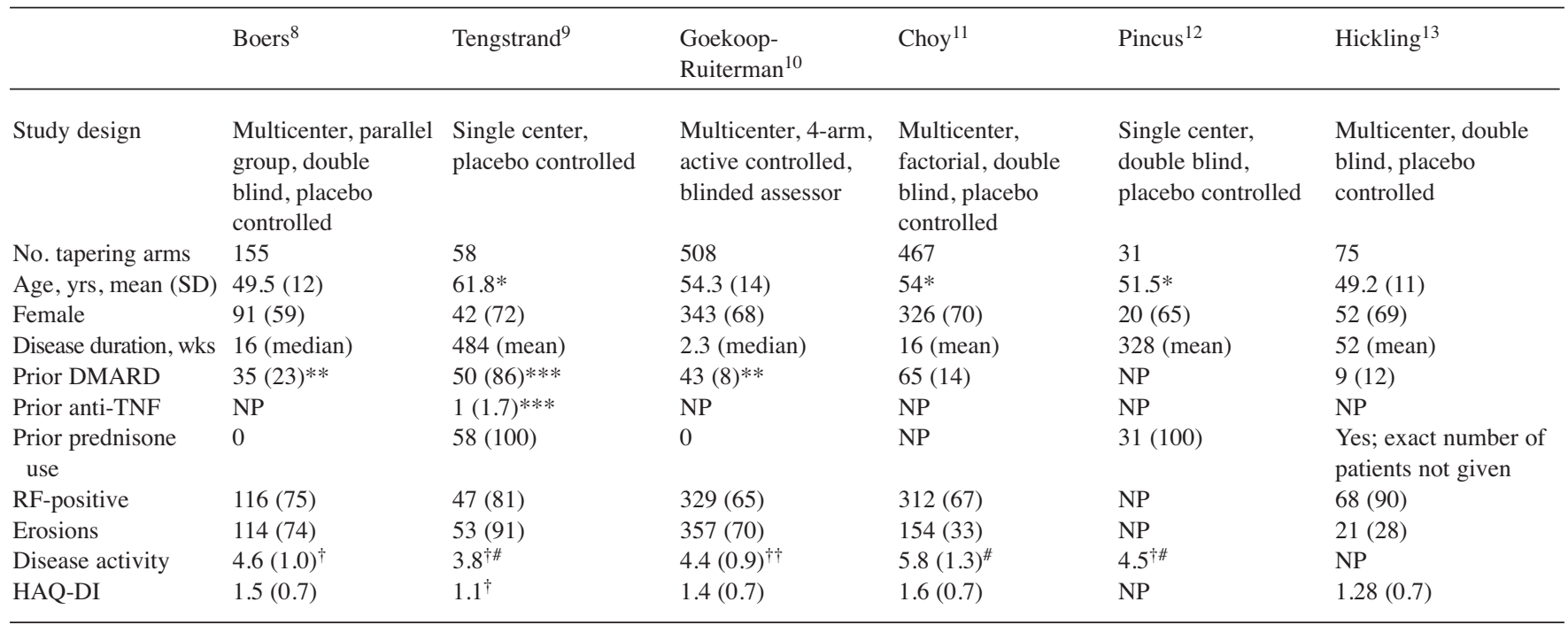

* Standard deviation (SD) not provided. ** Study reported only previous treatment with antimalarials. *** Current use of disease-modifying antirheumatic drugs (DMARD). ${ }^{\dagger}$ Disease activity score defined as a composite outcome measure containing the Ritchie tender joint index, swollen joint count, erythrocyte sedimentation rate, and the patient’s overall assessment. ${ }^{\dagger \dagger}$ Disease Activity Score defined by DAS-44. \# Disease Activity Score defined by DAS-28. NP: not provided; RF: rheumatoid factor; TNF: tumor necrosis factor; HAQ-DI: Health Assessment Questionnaire-Damage Index.

Table 2. Description of glucocorticoids (GC) tapering strategies. Values are $\mathrm{n}(\%)$, except where otherwise stated.

\begin{tabular}{|c|c|c|c|c|c|c|}
\hline & Boers $^{8}$ & Tengstrand ${ }^{9}$ & $\begin{array}{l}\text { Goekoop- } \\
\text { Ruiterman }^{10}\end{array}$ & Choy $^{11}$ & Pincus $^{12}$ & Hickling ${ }^{13}$ \\
\hline $\begin{array}{c}\text { Initial daily oral } \\
\text { GC dose, mg }\end{array}$ & Prednisolone 60 & Prednisolone 5-7.5 & Prednisone 60 & Prednisolone 60 & Prednisone $1-4$ & Prednisone 7.5 \\
\hline Taper protocol & $\begin{array}{l}\text { Weeks 1-6: weekly } \\
\text { decrease by } 20-38 \% \\
\text { of daily dose } \\
\text { Weeks } 7-28 \text { : } \\
7.5 \text { mg daily } \\
\text { Week } 29-34: 1 \text { day } \\
\text { of no GC for } 1 \text { st } \\
\text { week, then } 2 \text { days } \\
\text { of no GC for } 2 \text { nd } \\
\text { week, etc. } \\
\text { Week } 35: \text { No GC }\end{array}$ & $\begin{array}{l}\text { Decrease "very } \\
\text { slowly" by } 2.5 \mathrm{mg} \\
\text { in total weekly dose } \\
\text { once a week; patients } \\
\text { had "permission to } \\
\text { go slower if they } \\
\text { had withdrawal } \\
\text { symptoms" }\end{array}$ & $\begin{array}{l}\text { Decrease to } 7.5 \mathrm{mg} \\
\text { daily over } 7 \text { weeks; } \\
\text { if DAS44 } \leq 2.4 \\
\text { "persistently," } \\
\text { prednisone tapered } \\
\text { to } 0 \text { after } 28 \text { weeks } \\
\text { at undefined rate }\end{array}$ & $\begin{array}{l}\text { Decrease to } 7.5 \mathrm{mg} \\
\text { at } 6 \text { weeks; Week } \\
6-28: 7.5 \mathrm{mg} \text { daily; } \\
\text { Week } 29-34 \text { : tapered } \\
\text { to } 0 \text { at an undefined } \\
\text { rate }\end{array}$ & $\begin{array}{l}\text { Decrease by } 1 \mathrm{mg} \\
\text { every } 4 \text { wks }\end{array}$ & $\begin{array}{l}7.5 \mathrm{mg} \text { given every } \\
\text { other day for } 2 \mathrm{wks} \text {, } \\
\text { then every third day } \\
\text { for } 2 \mathrm{wks} \text {, then } \\
\text { discontinued }\end{array}$ \\
\hline $\begin{array}{l}\text { Successfully } \\
\text { tapered GC*** }\end{array}$ & $71(92)$ & $11(42)$ & $104(78)$ & $\mathrm{NP}$ & $5(31)$ & $31(86)$ \\
\hline
\end{tabular}

* Disease flare not explicitly defined. Study defined remission using American College of Rheumatology (ACR) preliminary criteria for remission, and the ACR preliminary criteria for improvement in rheumatoid arthritis. **Basis for stopping taper not explicitly defined. Remission defined as Disease Activity Score- $28<2.6$. ${ }^{* * *}$ Lowest GC dose was $0 \mathrm{mg}$ in all studies, except for Goekoop-Ruiterman, et al ${ }^{10}$, in which the lowest dose of GC was $7.5 \mathrm{mg}$ daily. NP: not provided in primary study; DAS: Disease Activity Score.

After all the effort, we discovered a great deal of variability and no satisfactory answer. Successful tapering was lowest in the 2 RCT in patients with longer disease duration; success rates were only $31 \%$ and $42 \%$ in patients with 6.3 and 9.3 years of disease, respectively ${ }^{9,12}$. All patients in these 2 studies had used oral GC prior to study entry. On the other hand, 2 studies evaluating GC-naive patients with a mean disease duration of $<2$ years reported 
success rates of $78 \%$ and $92 \%^{8,10}$. One study of early disease allowed prior GC and still the success rate in that study was $86 \%^{13}$.

In the LTE trials, successful tapering varied from $15 \%$ to $89 \%$, and control of RA with the biologic appeared to enable GC tapering and withdrawal. While successful tapering was a secondary efficacy outcome, none of the LTE trials reported data to examine changes in adverse effects.

No studies directly compared clinical outcomes in patients who tapered successfully versus those who tapered unsuccessfully. Only 1 study compared baseline disease characteristics of patients who tapered successfully versus those who tapered unsuccessfully, and reported that patients who tapered successfully were younger and a greater proportion were premenopausal ${ }^{9}$.

Despite a thorough and careful systematic literature review, we were disappointed to find that the data for tapering GC in RA were heterogeneous and incomplete. At this time, there is no credible way to provide an evidence-based answer to the question, "How do you taper GC in RA?"

It is possible, however, to suggest a way forward. It is clear that studies comparing GC tapering regimens are needed, and this systematic literature review uncovered important design features essential for such studies. First, it is probable that disease duration will influence success, and therefore tapering strategies for patients with early RA may differ compared with those for patients with established RA, who are likely to have been receiving GC chronically in varying doses. Second, the duration of tapering may not be as critical as the duration of disease and duration of prior GC use. Tengstrand, et $a l^{9}$ allowed up to 52 weeks to withdraw GC and yet the failure rate was $58 \%$. Third, it is clear that a robust outcome measure describing success would be appropriate, such as maintaining a Disease Activity Score-28< 3.2, Clinical Disease Activity Index $<11$, or any definition of remission. Fourth, it would be appropriate to consider a uniform definition of failure, such as RA flare of sufficient intensity and duration to result in a change in treatment. While not yet validated, such a definition is being developed using Outcome Measures in Rheumatology Clinical Trials RA flare criteria ${ }^{19}$. Fifth, studies should be designed to have enough power to create statistical models to detect important predictors of successful withdrawal, such as age, sex, and type of background RA therapy. Finally, and most importantly, improvements in safety, with regard to serious infection and cardiovascular events as well as bone effects, should also be considered as outcomes, acknowledging that such a study would require large numbers and longer followup.

Although we cannot answer the question of how to taper GC in RA, our review provides some background information and directions to design an appropriate clinical study to answer this important clinical question.
ELIZABETH R. VOLKMANN, MD; SHADI REZAI, MD,

Division of Rheumatology,

Department of Medicine,

University of California, Los Angeles, David Geffen School of Medicine,

Los Angeles, California;

SIMON TARP, MSc,

Musculoskeletal Statistics Unit,

The Parker Institute,

Department of Rheumatology,

Copenhagen University Hospital,

Frederiksberg, Copenhagen, Denmark;

THASIA G. WOODWORTH, MD; DANIEL E. FURST, MD,

Division of Rheumatology,

Department of Medicine,

University of California, Los Angeles,

David Geffen School of Medicine,

Los Angeles, California, USA

Address correspondence to Dr. D.E. Furst, Division of Rheumatology, Department of Medicine, University of California, Los Angeles, 32-59 Rehabilitation Center, 1000 Veteran Avenue, Los Angeles, CA 90095, USA.E-mail: defurst@mednet.ucla.edu

Dr. Volkmann is supported by The Specialty Training and Advanced Research (STAR) Program at UCLA. DEF and TGW are co-senior authors of this editorial. Dr. Furst receives grant/research support from Abbott, Actelion, Amgen, BMS, Gilead, GSK, NIH, Novartis, Pfizer, Roche/Genentech, and UCB; and acts as a consultant to Abbott, Actelion, Amgen, BMS, BiogenIdec, Centocor, Gilead, GSK, NIH, Novartis, Pfizer, Roche/Genentech, and UCB; and is a member of the speaker's bureau for Abbott, Actelion, and UCB (CME ONLY); and has accepted honoraria from Abbott, Actelion, Amgen, BMS, BiogenIdec, Centocor, Gilead, NIH, and Roche/Genentech.

\section{ACKNOWLEDGMENT}

We are indebted to Rikke Ogawa for assistance conducting the literature search.

\section{REFERENCES}

1. Criswell LA, Saag KG, Sems KM, Welch V, Shea B, Wells G, et al. Moderate-term, low-dose corticosteroids for rheumatoid arthritis. Cochrane Database Syst Rev 2000;2:CD001158.

2. Kirwan JR, Bijlsma JWJ, Boers M, Shea BJ. Effects of glucocorticoids on radiological progression in RA [review]. Cochrane Database Syst Rev 2007;1:CD006356.

3. Curtis JR, Westfall AO, Allison J, Bijlsma JW, Freeman A, George $\mathrm{V}$, et al. Population-based assessment of adverse events associated with long-term glucocorticoid use. Arthritis Rheum 2006;55:420-6.

4. Caplan L, Wolfe F, Russell AS, Michaud K. Corticosteroid use in rheumatoid arthritis: Prevalence, predictors, correlates, and outcomes. J Rheumatol 2007;34:696-705.

5. Gorter SL, Bijlsma JW, Cutolo M, Gomez-Reino J, Kouloumas M, Smolen JS, et al. Current evidence for the management of rheumatoid arthritis with glucocorticoids: A systematic literature review informing the EULAR recommendations for the management of rheumatoid arthritis. Ann Rheum Dis 2010;69:1010-4

6. Kirwan JR, Hickey SH, Hallgren R, Mielants H, Bjorck E, Persson $\mathrm{T}$, et al. The effect of therapeutic glucocorticoids on the adrenal response in a randomized controlled trial in patients with rheumatoid arthritis. Arthritis Rheum 2006;54:1415-21. 
7. Cochrane handbook for systematic reviews of interventions. Version 5.1.0. Higgins JPT, Green S, editors. [Internet. Accessed May 24, 2013.] Available from: www.cochrane-handbook.org

8. Boers M, Verhoeven AC, Markusse HM, van de Laar MA, Westhovens R, van Denderen JC, et al. Randomized comparison of combined step-down prednisolone, methotrexate and sulphasalazine with sulphasalazine alone in early rheumatoid arthritis. Lancet 1997:350:309-18.

9. Tengstrand B, Larsson E, Klareskog L, Hafstrom I. Randomized withdrawal of long-term prednisolone treatment in rheumatoid arthritis: Effects on inflammation and bone mineral density. Scand J Rheumatol 2007;36:351-8.

10. Goekoop-Ruiterman YP, de Vries-Bouwstra JK, Allaart CF, van Zeben D, Kerstens PJ, Hazes JM, et al. Clinical and radiographic outcomes of four different treatment strategies in patients with early rheumatoid arthritis (the BeSt study): a randomized controlled trial. Arthritis Rheum 2005;52:3381-90.

11. Choy EH, Smith CM, Farewell V, Walker D, Hassell A, Chau L, et al. Factorial randomised controlled trial of glucocorticoids and combination disease modifying drugs in early rheumatoid arthritis. Ann Rheum Dis 2008;67:656-63.

12. Pincus T, Swearingen CJ, Luta G, Sokka T. Efficacy of prednisone 1-4 mg/day in patients with rheumatoid arthritis: a randomized, double-blind, placebo controlled withdrawal clinical trial. Ann Rheum Dis 2009;68:1715-20.

13. Hickling P, Jacoby RK, Kirwan JR. Joint destruction after glucocorticoids are withdrawn in early rheumatoid arthritis. Arthritis and Rheumatism Council Low Dose Glucocorticoid Study Group. Br J Rheumatol 1998;37:930-6.
14. Kremer JM, Weinblatt ME, Bankhurst AD, Bulpitt KJ, Fleischmann RM, Jackson CG, et al. Etanercept added to background methotrexate therapy in patients with rheumatoid arthritis: continued observations. Arthritis Rheum 2003;48:1493-9.

15. Weinblatt ME, Keystone EC, Furst DE, Kavanaugh AF, Chartash EK, Segurado OG. Long term efficacy and safety of adalimumab plus methotrexate in patients with rheumatoid arthritis: ARMADA 4 year extended study. Ann Rheum Dis 2006;65:753-9.

16. Nishimoto N, Miyasaka N, Yamamoto K, Kawai S, Takeuchi T, Azuma J. Long term safety and efficacy of tocilizumab, an anti-IL-6 receptor monoclonal antibody, in monotherapy, in patients with rheumatoid arthritis (the STREAM study): evidence of safety and efficacy in a 5-yr extension study. Ann Rheum Dis 2009;68:1580-4.

17. Seror R, Dougados M, Gossec L. Glucocorticoid sparing effect of tumor necrosis factor alpha inhibitors in rheumatoid arthritis in real life practice. Clin Exp Rheumatol 2009;27:807-13.

18. Smolen JS, Aletaha D, Bijlsma JWJ, Breedveld FC, Boumpas D, Burmester G, et al. Treating rheumatoid arthritis to target: recommendations of an international task force. Ann Rheum Dis 2010;69:631-7.

19. Bartlett SJ, Hewlett S, Bingham CO 3rd, Woodworth TG, Alten R, Pohl C, et al. Identifying core domains to assess flare in rheumatoid arthritis: An OMERACT international patient and provider combined Delphi consensus. Ann Rheum Dis 2012;71:1855-60.

J Rheumatol 2013;40:1646-9; doi:10.3899/jrheum.130019 